\title{
JÜRGEN HABERMAS Y EL RIESGO DE LA EUGENESIA LIBERAL PARA LA AUTOCOMPRENSIÓN ÉTICA DE LA ESPECIE
}

\author{
JÜRGEN HABERMAS AND THE RISK OF LIBERAL EUGENICS FOR THE ETHICAL \\ SELF-UNDERSTANDING OF SPECIES
}

\author{
MARC PALLARÉS PIQUER \\ Universidad Jaume I y Universidad Internacional de la Rioja \\ pallarem@uji.es \\ ÓSCAR CHIVA BARTOLL \\ Universitat de València, \\ oscar.chiva@uv.es
}

RECIBIDO: $22 / 7 / 2016$
ACEPTADO: $19 / 9 / 2016$

Resumen: El artículo analiza el problema de la naturaleza humana que presenta Jürgen Habermas en su obra El futuro de la naturaleza humana, ¿Hacia una eugenesia liberal? Los vertiginosos avances biotecnológicos reclaman una rigurosa reflexión bioética que el filósofo alemán afronta superponiendo a su ética del discurso una ética de la especie. Habermas esboza un modelo de naturaleza humana construido sobre preceptos como la dignidad humana y de la vida humana, la simetría de las relaciones intersubjetivas y, a resultas de estas, la autocomprensión ética de la especie. Respecto a la eugenesia liberal, el autor se posiciona criticando la eugenesia positiva y amparando la negativa, para lo que basa su argumentación en torno a la constitución de dos tipos de humanidad: la genéticamente mejorada y aquella no intervenida genéticamente. Finalmente, el artículo aborda las principales críticas vertidas sobre el planteamiento habermasiano.

Palabras clave: bioética, naturaleza humana, manipulación genética, eugenesia liberal, Habermas.

\begin{abstract}
The article analyzes the problem of human nature that presents Jürgen Habermas in his work The future of human nature, Towards a liberal eugenics? The rapid advances in biotechnology demand a rigorous bioethical reflection that the German philosopher confronts superimposing to his ethics of the discourse a new ethics of the species. Habermas outlines a model of human nature built on precepts such as human dignity and dignity of the human life, symmetry of people's interrelationships and, as a result of these, the ethical self-understanding of the species. Regarding the liberal eugenics, the author criticizes positive eugenics and protects the negative one, for which bases its argument about the existence of two types of humanity: the genetically enhanced and that genetically intact. Finally, this paper discusses the main criticisms about the Habermasian approach. Keywords: bioethics, human nature, genetic manipulation, liberal eugenics, Habermas.
\end{abstract}




\section{La necesaria reflexión ética sobre la eugenesia liberal}

El amanecer del s. XXI ha presenciado un avance tecnológico sin precedente muy difícil de comparar con cualquier otra época histórica. Paralelamente, en contraposición a una visión plenamente optimista del progreso tecnológico, se ha ido abriendo camino (de manera tan lenta como necesaria) una valoración crítica de dicho desarrollo. Poco a poco la conciencia de los problemas ético-filosóficos, que plantean las aplicaciones indiscriminadas de las nuevas tecnologías, ha calado en la opinión pública (García Moreno, 2004), hasta el punto de que autores como López Araiza (2012) defienden la existencia de una filosofía de la tecnología de modo independiente a la filosofía de la ciencia.

Un tema nuclear de esta nueva rama de la filosofía podría atribuirse al determinismo tecnológico, entendido como la ausencia de control de la tecnología por parte del ser humano. Aunque, como advierte acertadamente Diéguez (2011), la plausibilidad inicial del determinismo tecnológico no se sostiene ya que, aun cuando fuera cierto que nada podemos hacer para evitar que a la tecnología avance a un ritmo arrollador, ello no debería llevarnos a concluir que no cabe condenar su realización y exigir responsabilidades morales y legales a los causantes.

Es palmario que el desarrollo tecnológico trae consigo un ineludible proceso de cambio social (Queraltó, 2002) que acarrea nuevos problemas ético-sociales ante los que, como advierten Villalobos y Bello (2014: 76), se necesita una "relación simbiótica entre las tecnologías y la bioética como saber práctico/teórico", que además "tenga un carácter menos moralizante y más político-económico" (Mendieta, 2002:91). La fuente de una parte importante de estos problemas emana de todo lo relacionado con la investigación del genoma humano, en tanto que es un campo que genera controversias que no afectan sólo a lo relativo a las condiciones materiales de la vida, sino también a la propia organización interna y a los valores y creencias compartidos que, en definitiva, conforman la cultura (García Moreno, 2004).

Con el descubrimiento del ADN, Watson y Crick abrieron una nueva era en la historia de la humanidad. Acto seguido, el consiguiente estudio sobre cómo modificarlo dio lugar a la biotecnología; entendida como disciplina que se encarga de mejorar -e incluso crear- mediante la manipulación genética, las especies existentes. La ingeniería genética da al ser humano la capacidad de alterar los conceptos de naturaleza y vida, permitiéndole jugar a ser el creador de nuevos seres determinados genéticamente. Es por ello por lo que se necesita imperativamente una bioética capaz de orientar la carrera tecnológica en aras de una regulación justa y racional. 
La bioética, término acuñado por Van Rensselaer Potter, emergió como campo del conocimiento en la década de los 70s del siglo pasado (Villalaín Blanco, 2001); y a medida que ha ido cruzando fronteras y abriéndose a nuevas temáticas y culturas, se ha ido pertrechando de principios que la han ido enriqueciendo y actualizando (López Baroni, 2011). En su génesis fueron cuatro los famosos principios que la constituían alrededor de dos temas concretos, el aborto y la eutanasia. Sin embargo, con el paso de los años ha aumentado la complejidad con fenómenos como la clonación, los transgénicos o las células madre; produciéndose, a comienzos del siglo XXI, un nuevo giro de consecuencias impredecibles, a saber, el estudio del genoma humano ha hecho posible el desarrollo de terapias genéticas $\mathrm{y}$, en consecuencia, ha provocado también un exacerbado interés económico por la explotación de estas tecnologías (López Baroni, 2013).

El caso es que la posibilidad de que los manipulados genéticamente seamos los seres humanos está llamando a la puerta del pertinente debate bioético. En particular, estos avances recientes en biotecnología están desencadenando una avalancha de reflexiones y especulaciones que, como advierten Bostrom (2011) y Mendieta (2002), van desde la habitual retórica apocalíptica sobre un mundo feliz genéticamente programado, hasta la idea de que cualquier intento de regulación implicaría bloquear el camino hacia una sociedad futura más preparada para afrontar sus proyectos vitales. Por una parte, si se cumpliera lo primero, se abriría la puerta a una forma feroz y sofisticada de eugenesia, promovida en la actualidad por el discurso del neoliberalismo y la medicina mercantilizada; pero, por otra parte, los detractores de la regulación esgrimen con idéntico énfasis y convicción, que la genómica puede ser la clave para resolver gran parte de los problemas sociales a los que se enfrentarán las sociedades del futuro.

Ante la necesidad de una rigurosa reflexión bioética, el presente artículo ofrece la visión que el filósofo alemán Jürgen Habermas (2002) ofrece en su obra El futuro de la naturaleza humana, ¿Hacia una eugenesia liberal?, desde la que, como se verá, superpone a su ética del discurso una (bio) ética basada en la autocomprensión ética de la especie.

\section{Jürgen Habermas: ética del discurso y reflexiones sobre la técnica}

Jüegen Habermas es un conocido filósofo y sociólogo alemán nacido en Düsserldorf en 1929. Destaca como exponente de la segunda generación de la Escuela de Fráncfort, iniciada por Max Horkheimer y Theodor Adorno en torno 
al proyecto de una Teoría Crítica referida a la praxis y enmarcada en el contexto de un materialismo marxista que determina la conexión entre teoría y praxis. En resumidas cuentas, la Escuela de Fráncfort, desde un enfoque multidisciplinar, se ha mostrado fiel a los ideales ilustrados, abogando por una sociedad fundada en la razón, entendida esta como una razón práctica enraizada en el mundo de la vida.

Siguiendo la tradición deontológica kantiana, el principal legado éticofilosófico de Habermas orbita en torno a la definición de una ética discursiva o dialógica, compartiendo parte de su concepción con el también significado filósofo Karl Otto Apel. Concretamente ambos plantean que la razón humana es dialógica y que, por tanto, sólo a través de un diálogo entre los afectados se puede decidir qué normas son correctas. Este planteamiento se apoya en una vertiente procedimental que constituye una excelente posibilidad para las éticas aplicadas.

Inicialmente la ética del discurso fue concebida en los años setenta del siglo pasado. También es conocida como teoría de la acción comunicativa $\mathrm{y}$, entre otros aspectos, puede decirse que destaca por ser una teoría más preocupada por la corrección de las normas que por la verdad de las proposiciones. Es decir, por el discurso práctico (normas correctas) que por el teórico (proposiciones verdaderas), aunque satisface en gran medida ambos planteamientos (Habermas, 2000).

Con su teoría Apel y Habermas abrían la puerta al mundo de la intersubjetividad y el reconocimiento recíproco como fundamento de la obligación moral, ya que, desde su posición, cualquiera que realiza una acción comunicativa está reconociendo que su interlocutor también está dotado de competencia comunicativa, estando ambos ligados por un vínculo comunicativo. Por otra parte, para comprender mejor lo que estos autores quieren significar al hablar de acción comunicativa, ésta puede clarificarse en contraste con la acción estratégica. Así, mientras que la acción comunicativa es aquella en la que los interlocutores coordinan sus proyectos e iniciativas personales a través del lenguaje y el entendimiento mutuo como medio necesario, la acción estratégica es aquella en la que el hablante y el oyente se instrumentalizan entre sí para alcanzar sus intereses personales, tratándose mutuamente como medios y no como fines.

Para poder aceptar el estatus racional de acción comunicativa ésta debe contar con una serie de condiciones. Concretamente, estas condiciones son cuatro y se definen en conjunto como pretensiones de validez del habla. Para que éstas se cumplan se ha de presuponer que: (1) el emisor pretende que lo que dice es inteligible, (2) que está siendo sincero, (3) que lo que dice es verdadero y (4) 
que se desenvuelve en el marco de normas correctas. Estas cuatro pretensiones de validez del habla han de ser aceptadas implícitamente en el transcurso de su acción comunicativa tanto por el emisor como por el receptor. En cuanto a los nombres que desde la ética discursiva se atribuyen a cada una de las cuatro pretensiones de validez del habla, siguiendo el orden recién descrito, éstas son conocidas como: (1) inteligibilidad, (2) veracidad, (3) verdad y (4) corrección. El principio de la ética discursiva afirma que sólo pueden pretender validez aquellas normas que logran o podrían lograr la aprobación de todos los afectados como participantes en un discurso práctico (Habermas, 1991). Es decir, que únicamente serían válidas las normas que, después de celebrarse un discurso simétrico, fueran aceptadas por todos los interlocutores. No obstante, aunque esta situación es, como el propio nombre indica -ideal-, en principio debe comprenderse como una idea regulativa.

En este sentido, la ética discursiva puede clasificarse como una ética deontológica ya que no se ocupa directamente de la felicidad ni de las consecuencias, sino de proporcionar un procedimiento racional con el que decidir qué normas son correctas. Un procedimiento basado en la celebración de un diálogo entre todos los afectados por las normas y cuyo desenlace culmine en un acuerdo motivado por la fuerza de los argumentos allí esgrimidos. Sin embargo, cabe advertir que aunque la medida de las consecuencias no sea su cometido, la ética del discurso sí exige tenerlas en cuenta en el momento de la aplicación de las normas resultantes (Cortina, 1993).

En lo relativo específicamente a la reflexión sobre la técnica, puede decirse que la Teoría Crítica de la Escuela de Fráncfort establecía una identificación que relacionaba la técnica con el propio sistema capitalista, es decir, con el predominio del economicismo mercantilista, en el que el hombre acaba convirtiéndose en un medio para el hombre. Sin embargo, Habermas, en las reflexiones de su Ciencia y técnica como ideología (2002), se distancia tomando un posicionamiento menos radical en el que asume el carácter imprescindible de la técnica, admitiendo su correspondencia estructural con el ser humano. En este punto, el autor alemán se apoya en una visión antropológica de la técnica al considerar que esta adopta una relación directa con la satisfacción de las necesidades humanas. Es decir, entiende la técnica como una instrumentalización de funciones originalmente orgánicas que ayudan a las personas a descargarse de determinadas necesidades propiamente humanas. De manera que, aceptando el contenido político de la tecnología, para Habermas (2002) la técnica representa un proyecto de la especie humana en su conjunto, que debe someterse a la pertinente reflexión ética para distinguir entre los intereses específicos de la 
especie humana (universalizables) que subyacen al desarrollo tecnológico y los intereses particulares (éticamente reprochables).

\section{De la ética del discurso a la ética de la especie}

Como hemos visto, Habermas se erige como un heredero crítico de la Escuela de Fráncfort que no ha dejado de perfilar su proyecto con la preocupación por reconstruir una esperanza en la razón, añadida a la construcción de una ética del discurso. Asimismo, asumiendo la técnica como correspondencia estructural del ser humano, en su obra El futuro de la naturaleza humana, ¿Hacia una eugenesia liberal?, aborda los desafíos a los que las biotecnologías confrontan nuestra moderna comprensión de la libertad. Como diría Queraltó (2002), ante un problema de otra índole, una respuesta ética diferente. Por lo que el filósofo alemán superpone a la ética del discurso una ética de la especie basada en la autocomprensión ética de los individuos.

Conforme a lo visto en el anterior apartado, la ética del discurso remite a un procedimiento formal (exento de contenido) orientado a la construcción de normas que aspira a tomar en consideración los intereses de todos los afectados y partícipes del procedimiento discursivo. Este procedimiento radica, de base, en la autonomía de los participantes para expresar libremente sus intereses y en la simetría de los participantes en cuanto al valor igual de sus argumentos. En este sentido, la fiabilidad radica en que el discurso realizado siempre puede someterse a revisión, y la validez emana de la aceptación del argumento consensuado en tanto que continente del interés común. Sin embargo, la manipulación genética podría poner en entre dicho estos preceptos, ya que los interventores (padres) podrían actuar instrumentalizando a los intervenidos (no-natos), quebrando la autonomía y simetría de partida.

Por vez primera, de la mano de la ingeniería genética y de la embriología, nuestra propia esencia, o naturaleza humana, es susceptible de sufrir manipulaciones genéticas. En este caso, lo que está en juego ya no es la adaptación de un avance tecnológico a nuestras concepciones y realidades sociopolíticas, sino la reflexión sobre nuestra propia autocomprensión como especie, a la luz de un avance tecnológico que según Habermas pone en cuestión lo que significa ser humano (Mendieta 2002). El autor germano toma parte y entra en este diálogo entre la bioética y la biotecnología en la referida obra ( $E l$ futuro de la naturaleza humana. ¿Hacia una eugenesia liberal), que apareció originariamente en el otoño de 2001 como consecuencia de una polémica 
mantenida con Peter Sloterdjk a raíz de su conferencia publicada bajo el título Normas para el parque humano.

De forma muy sintética la obra se articula en torno a una tesis central que mantiene que los sujetos manipulados genéticamente no podrán concebirse a sí mismos como autores únicos de sus proyectos vitales (pérdida de autonomía). Además, Habermas esgrime que los humanos sometidos a manipulación genética no se considerarán como iguales (pérdida de simetría) respecto a las generaciones antecesoras porque estas habrían socavado su autonomía al apropiarse de sus futuros proyectos de vida. Así, plantea que la regulación de la eugenesia liberal está sujeta a la manera en que deseemos comprendernos, de una manera general, como miembros de la especie humana.

Es por ello que al ver amenazado el constructo sobre el que se sustenta la ética del discurso (de la mano de las posibles consecuencias de la eugenesia liberal), el filósofo alemán se ve obligado a implementarla con esta ética de la especie. Pues, como apunta Moreno Lax (2008: 108): "No es posible garantizar las condiciones ideales de las reglas del discurso práctico sin antes conservar una ética de la especie que preserve la libertad de cada individuo para comprender críticamente su propia historia personal."

De esta manera, la controversia referida a las diferentes visiones del ser humano que están en concurrencia adquiere una significación ética que atañe, en su conjunto, a la especie humana. Para tratar esta cuestión Habermas esboza un modelo de naturaleza humana basado en la autocomprensión ética de la especie. A continuación abordamos dicho planteamiento, no sin antes aclarar brevemente las principales controversias que genera en sí el propio concepto de naturaleza humana.

\section{Naturaleza humana: la autocomprensión ética de la especie}

En la obra El futuro de la naturaleza humana. ¿Hacia una eugenesia liberal? vemos como el autor muestra, desde el mismo título, un punto de partida desde el que acepta y da cabida en su reflexión a la existencia de una naturaleza humana. La pregunta sobre la existencia de la naturaleza humana busca su respuesta en torno a aquello que todos tenemos en común. A esto se le suele llamar esencia o naturaleza. El debate acerca de qué es la naturaleza humana (y si realmente existe) ha dado lugar a interpretaciones tan variadas y a polémicas tan inacabables que, antes de estudiar en qué consiste, conviene esclarecer las dificultades que encierra este concepto, así como lo que podemos esperar de él. 
A la pregunta ¿qué es la naturaleza humana? Manuel Gil Antón (2005), responde en clave epistemológica con el siguiente argumento: todo proceso científico, para ser tal, opera con conceptos (Weber). Todo concepto científico es una libre invención del intelecto humano (Einstein), o en otras palabras, uno no sabe lo que ve, sino que ve lo que sabe mediado por conceptos (Piaget). Por tanto, la naturaleza humana no puede ser algo en sí definible de una vez para siempre, sino una noción perteneciente a la región de los fenómenos que implica la mediación de los humanos a través de conceptos. De esta forma, lo que la naturaleza humana es o puede ser enunciada como lo que es, es una resultante de nuestra relación cognitiva con la realidad.

En su obra La naturaleza humana, el filósofo de la ciencia Jesús Mosterín (2006) hace un recorrido por el debate acerca de la presunta inexistencia de la naturaleza humana alentada por parte de determinados filósofos, humanistas y pensadores a lo largo de la historia. Encontramos tanto defensores como detractores de la naturaleza humana. Entre los primeros destaca David Hume (1711- 1776), firme defensor de la naturaleza humana entendida como eje y denominador común en la conducta de los hombres de las distintas naciones y edades. Entre los detractores destacan Ortega y Gasset (1883-1956), que niega la existencia de la naturaleza humana. Para Ortega el hombre no tiene naturaleza, sino que tiene historia. O por su parte Jean Paul Sartre (1905-1980) y los existencialistas, quienes pensaban que el hombre carece de naturaleza, que en él la existencia y la libertad preceden a la esencia y la determinación. Así como John Watson (1878-1958), quien desde su posición acérrima del conductismo, negaba la naturaleza humana en cuanto que creía que todo era obra del condicionamiento (posición similar a los ilustrados Condillac y Helvetius). Por otra parte, Johan G. Fichte (1762-1814) defendía la libertad absoluta del yo; y Karl Marx (1818-1883) pensaba que la naturaleza humana era el resultado de las relaciones de producción. Finalmente, el propio Jesús Mosterín mantendrá que el avance actual en materia científica, y concretamente en la exploración del genoma humano, hace insostenible cualquier negación de nuestra naturaleza.

Para seguir avanzando en el análisis, pasaremos a acotar y concretar la noción que mantiene Habermas en torno a la médula de su modelo de naturaleza humana, a saber, la autocomprensión ética de la especie. Este hecho es el que, según su concepción, nos convierte en seres humanos. Para acotarlo optamos por abordar los siguientes conceptos e ideas vertidos en su obra: dignidad humana y dignidad de la vida humana, simetría de las relaciones intersubjetivas y, como consecuencia de las anteriores, la autocomprensión ética de la especie. 


\section{Dignidad humana y dignidad de la vida humana}

En términos morales la dignidad humana se entiende como un "a priori", como una categoría moral. Se trata de una dignidad ontológica, que se posee en función de la condición humana y que no depende ni de la propia conducta ni de cualquier ente institucional externo. La dignidad, al ser común a todos los seres humanos, nos hace iguales y acreedores de igual consideración y respeto. Por ello, el eje fundamental sobre el que articular cualquier reflexión ética sobre el genoma humano no deja de ser el propio concepto de dignidad.

La dignidad a la que apela Habermas mantiene cierta vinculación con la dignidad que definió Kant (1989) en el Capítulo III de su Metafísica de las Costumbres. Para Kant la dignidad personal residía en la autonomía de la voluntad y de la libertad. Encontramos en Habermas, sin embargo, un matiz basado en el sentido moral, que nos habla del reconocimiento mutuo de esa autonomía de la voluntad y de la libertad. Por lo tanto, para nuestro autor, la dignidad cobra sentido en el reconocimiento recíproco y en el trato entre las personas.

En cualquier caso, Habermas (2002:50) diferencia las expresiones dignidad de la vida humana, referida a los no-natos o a los seres humanos después de su muerte, la cual sería para él indisponible; y por otra parte nos habla de la dignidad humana, referida a los seres vivos nacidos, y que sería de carácter inviolable y basada, en sentido moral, en la simetría entre las relaciones.

La «dignidad humana» en estricto sentido moral y legal está ligada a esta simetría de las relaciones. No es una propiedad que se posea por naturaleza, (...) sino que más bien destaco aquella «inviolabilidad» que únicamente tiene algún significado en las relaciones interpersonales de reconocimiento recíproco, en el trato que las personas mantienen entre ellas.

En cuanto al tema de la inviolabilidad y la indisponibilidad nos apoyaremos en Germán Zurriaraín (2005), para clarificar que Habermas deja abierto el tema de la diferencia entre inviolabilidad e indisponibilidad. El primer término parece tener un carácter absoluto. El segundo estaría abierto a grados, pero no concreta la gradualidad de dicho término y en razón de qué se atribuye dicha gradualidad. En consecuencia, podemos extraer que lo constitutivo de la dignidad humana, para Habermas, es la inviolabilidad. Una inviolabilidad que como él mismo indica, encuentra significado en las relaciones interpersonales de reconocimiento recíproco. Así pues la dignidad, como atributo de su modelo antropológico, 
aunque en estricto sentido moral, encuentra sentido a partir del trato y la relación entre personas.

\section{Simetría de las relaciones intersubjetivas}

El concepto de simetría de las relaciones intersubjetivas aparece en la ética habermasiana como garante de la autonomía del sujeto ante cualquier determinación procedente de otro, contribuyendo además a preservar la conciencia de sí mismo (Rius, 2004). En la obra El futuro de la naturaleza humana, ¿Hacia una eugenesia liberal?, Habermas no otorga al embrión una protección absoluta, en tanto que no existe una relación simétrica entre este y quien pudiera interceder en su configuración genética. Aunque, por otra parte, tampoco trata a la vida humana prepersonal como un bien susceptible de ser sometido a la competencia de un mercado liberal.

El nacimiento, como acto socialmente individualizador, constituye a un organismo humano en una persona susceptible de mantener relaciones intersubjetivas simétricas con otros. Como indica Germán Zurriaraín (2005), la naturalidad del nacimiento desempeña el papel conceptualmente exigible a la anteriormente aludida indisponibilidad. Para Habermas, el estatuto ontológico del no-nato, en tanto vida humana, radica no en lo que es antes de nacer, sino en lo que será desde el momento del nacimiento. Es en ese momento en el que se inicia la simetría efectiva de las relaciones intersubjetivas. Sin embargo, hasta ese momento, el autor tampoco acepta que la vida humana prenatal sea susceptible de abordarse con fines relativos a la instrumentalización (inviolabilidad).

Ante esta cuestión destaca el trasfondo de individualización social, al que Habermas apela para otorgar al embrión el estatuto ontológico de individuo de la especie humana tras su nacimiento. De este modo, empezamos a vislumbrar la importancia de la dimensión social y de la relación intersubjetiva de igualdad y simetría dentro del modelo antropológico sobre el que se basa Habermas (2002:25), tal como observamos claramente cuando dice:

Lo que hoy se pone a disposición es algo diferente: la indisponibilidad de un proceso contingente de fecundación cuya consecuencia es una combinación imprevisible de dos secuencias cromosómicas distintas. Esta contingencia insignificante se revela -en el momento en que es dominada- como un presupuesto necesario para el poder ser sí mismo y para la naturaleza fundamentalmente igualitaria de nuestras relaciones interpersonales. 
En definitiva, resulta interesante en este sentido que observemos la posición que mantiene el filósofo alemán en relación al estatus del no-nato. Aunque no percibe al embrión como un ser humano, sí que le otorga el estatus de un vida humana que debe ser protegida, por eso desarrolla una distinción entre dignidad humana y vida humana (Bobadilla, 2003).

Así pues, Habermas trata de establecer un equilibrio en el que otorga cierto valor a la vida del embrión para protegerla de una instrumentalización al servicio de los intereses del mercado. Sin embargo, se niega a otorgar al embrión humano un estatuto ontológico personal antes de su nacimiento.

\section{Autocomprensión ética de la especie}

Los preceptos anteriores (dignidad humana y de la vida humana y simetría en las relaciones intersubjetivas), conducen al ser humano al estado de autocomprensión ética de la especie, definido por Habermas como eje medular de su modelo antropológico. Para el autor germano, si se diera el caso de romperse la igualdad y la simetría entre seres, los pilares sobre los que se fundamenta ese estatuto moral se derrumbarían, con lo cual existiría un sentido diferenciador entre la naturaleza de los seres manipulados genéticamente respecto a los que no. En palabras del propio Habermas (2002: 37-38): "La manipulación de los genes afecta a cuestiones de identidad de la especie, y la autocomprensión del ser humano como ser perteneciente a una especie también conforma el lecho de nuestras representaciones legales y morales."

Por tanto, el estatuto moral que alcanzamos al coexistir como seres iguales, libres y autónomos constituye la base de la autocomprensión autónoma de uno mismo y, por ende, de su propia biografía. En este sentido argumenta que:

Urge preguntarse si la tecnificación de la naturaleza humana modificará la autocomprensión ética de la especie de manera que ya no podamos vernos como seres vivos éticamente libres y moralmente iguales, orientados a normas y razones ( $\mathrm{p}$. $60)$.

De hecho, como dice Habermas (2002), lo que Kant consideraba «el reino de la necesidad» se ha transformado con la Teoría de la evolución en el «reino de la casualidad»; y ahora, la tecnología genética lo desplaza constituyéndolo en el «reino de la libertad». Esta ampliación de la contingencia de nuestra naturaleza 
modifica la estructura de nuestra experiencia moral, pudiendo condicionar la propia autocomprensión de la especie:

El desplazamiento de las «fronteras entre casualidad y libre decisión» afecta a la autocomprensión en total de personas que actúan moralmente y están preocupadas por su existencia. Nos hace ser conscientes de nuestra autocomprensión moral y un trasfondo ético referido a la especie (p. 60).

La intervención genética, según el autor, perturbaría entonces nuestra comprensión ética de la especie porque al someter a los individuos manipulados al controvertido proceso de "cosificación", romperíamos con la plena autoría de su propia biografía, puesto que en ellos se daría una disminución de la autonomía personal que los seres humanos nos reconocemos mutuamente. Es decir, si los padres actuaran en el proceso de elección de cualquier carácter genético, podrían proclamarse en ese momento coautores, junto con el futuro individuo, de la biografía del mismo,

Las intervenciones eugenésicas perfeccionadoras menoscaban la libertad ética en la medida que fijan a la persona afectada a intenciones de terceros que rechaza pero que, al ser irreversibles, le impiden comprenderse espontáneamente como el autor indiviso de la propia vida (p. 87).

Así pues, parece quedar claro que la autocomprensón ética de la especie resulta incompatible con la intervención genética, pues esta impediría la autocomprensión autónoma de uno mismo y, por ende, de su propia biografía. Entendemos por tanto que según Habermas, la eugenesia liberal traería al mundo seres cuya comprensión de sí mismos y de exclusividad en la autoría de su biografía no se daría; con lo cual podríamos afirmar que los hijos de la eugenesia liberal participarían de una naturaleza humana diferente.

\section{Eugenesia liberal: eugenesia positiva y/o eugenesia positiva}

La eugenesia, del griego eugoniké, significa buen origen, y relacionada con el parentesco, se entendería como bien nacido. Es un concepto que alude a la mejora de los rasgos humanos hereditarios mediante formas de manipulación genética. Como indicábamos al inicio del artículo, los nuevos avances de la ingeniería genética humana han auspiciado un resurgimiento de la eugenesia. Mientras que la eugenesia autoritaria clásica (basada en el emparejamiento programado de los progenitores) buscaba producir ciudadanos que se ajustaran a 
un solo modelo, la marca distintiva de la nueva eugenesia liberal sería la neutralidad del estado frente a la participación (más o menos caprichosa) de los padres (Agar, 2012). En palabras del propio Habermas (2002) la eugenesia liberal se define como "una praxis que deja al parecer de los padres las intervenciones en el genoma del óvulo humano fecundado" (p. 105).

La eugenesia liberal se abre camino a través de dos vías diferenciadas, la que interviene para alterar la condición de un padecimiento y curar al paciente (eugenesia negativa), y la que busca alterar la condición natural y garantizar mejores genes para la vida de las personas (eugenesia positiva). En El futuro de la naturaleza humana, ¿Hacia una eugenesia liberal?, Habermas (2002) plantea una previsión de las graves implicaciones éticas que podría acarrear la eugenesia liberal. De hecho, al defender esta tesis se ve obligado a señalar y clarificar la oposición entre la eugenesia positiva y la eugenesia negativa, ofreciendo toda una serie de elementos de juicio que le llevarán a defender la eugenesia negativa y a mostrar su discrepancia con la positiva:

Así, por ejemplo, en el caso de las intervenciones genéticas terapéuticas tomamos el embrión como la segunda persona que será alguna vez. Esta actitud clínica obtiene su fuerza legitimadora de la fundamentada suposición contrafáctica de que es posible el consenso con otro que puede decir «si» o «no» $(\ldots)$.

En todo caso un consenso solo puede darse por supuesto cuando se trata de evitar males indudables y extremos que es de esperar que todos rechacemos.

Es el punto de vista moral de no dar un trato instrumentalizador a segundas personas, lo que como quisiera mostrar, nos reafirma en la «lógica de la curación» y nos impone -al contrario que el emotivo espacio de tolerancia de una eugenesia liberal- la carga de trazar las fronteras entre la eugenesia negativa y la eugenesia perfeccionadora (pp. 63-64)

Como hemos visto, Habermas rechaza la eugenesia liberal aduciendo dos posibles consecuencias que socavarían la autonomía y simetría personal de los implicados. Por una parte advierte que las personas manipuladas genéticamente podrían dejar de verse como autoras de su propia biografía; y, por la otra, indica que además estas personas podrían dejar de contemplarse como personas de igual condición respecto a las generaciones precedentes que han promovido la manipulación.

En este sentido, el autor refleja su estremecimiento ante la amenaza de la eugenesia liberal, dado que el mercado reduciría al embrión humano al valor de $\cos a$, lo cual podría romper nuestra propia concepción ética como seres iguales y simétricos $\mathrm{y}$, según lo argumentado en el apartado anterior, la propia autocomprensión ética de la especie: 
Por eso nos inquieta la pregunta de si, y cómo, un acto cosificador de este tipo afectaría a nuestro poder ser sí mismo y a nuestra relación con los demás. ¿Podríamos entendernos todavía como personas que se comprenden como autores indivisos de sus vidas y que salen al encuentro de todos los demás sin excepción como personas de igual condición? (p. 98).

No obstante, aun partiendo de este punto, el autor no titubea al aceptar la eugenesia negativa en tanto que descansaría en una acción comunicativa virtual entre sujetos (Cortina, 2008). De este modo los interlocutores que actuaran como interventores (los padres a través del terapeuta) podrían evitar problemas de salud extremos que todos rechazaríamos por consenso, de manera que el propio afectado (entendido como interlocutor potencial futuro) podría aceptarla, desapareciendo así la posible colisión de intereses entre la decisión de los padres y la libertad ética de los hijos. Así, en última instancia, no se pondría en peligro la capacidad del individuo manipulado genéticamente para actuar y desarrollar su proyecto de vida con plena autonomía.

Sin embargo, el autor alemán se posiciona en contra de la eugenesia positiva, que aspira a fines de mejora, en tanto que en esta acción un sujeto instrumentaliza a otro tratándolo como un objeto (Cortina, 2008). Este hecho menoscabaría la libertad ética de los afectados por la intervención genética, pues habrían estado sujetos a intenciones de terceros y, en consecuencia, se habría visto vulnerada la simetría de las relaciones intersubjetivas a la que aludíamos en apartados anteriores. Este hecho, a su vez, impediría que cada individuo afectado se comprendiera como autor pleno de su proyecto de vida, teniendo este hecho consecuencias irreversibles.

Habermas argumenta que en la eugenesia negativa se sobreentiende que en un diálogo posterior, el no-nato estaría de acuerdo sin lugar a dudas, con la decisión tomada por los padres, con lo cual, traslada el diálogo a un presentefuturo en el que da por sentadas las posturas y conclusiones del mismo. Sin embargo, este hecho no se daría con la misma seguridad en un acto de eugenesia positiva, en tanto que se podría estar condicionando el proyecto de vida del nonato de manera no necesariamente acorde a sus propios intereses y, por consiguiente, podría incluso implicar una amenaza hacia la autocomprensión del ser humano como especie. 


\section{Consideraciones finales}

Los avances tecnológicos amenazan la forma de entender nuestra propia naturaleza, dejando en manos del ser humano la capacidad de modificar su propia esencia biológica. Con el conjunto de planteamientos que Habermas despliega en su obra, defiende la implantación de ciertas consideraciones normativas que entiende necesarias para evitar la creación de un comercio de embriones basado simplemente en las leyes de la oferta y la demanda, y centrado en las posibilidades de intervención genética que, previsiblemente, en un futuro no muy lejano podrían brindarnos las biotecnologías.

Habermas hace un llamamiento a la necesidad de la reflexión filosófica para establecer límites normativos al avance de la biotecnología, con la intención de preservar, según sus propios planteamientos, nuestra autocomprensión ética como especie. Una comprensión ética basada en nuestra autonomía, nuestra libertad y nuestra igualdad como individuos. Elementos, todos ellos, que con la eugenesia liberal sufrirían una transformación radical que afectaría a la autoconciencia previa que acompaña todas nuestras actividades $\mathrm{y}$, por ende, nuestros proyectos de vida. Es decir, si las reglas de este juego moral variaran, nuestra comprensión ética como especie se modificaría y, con ello, según el autor, probablemente abriríamos las puertas a una naturaleza posthumana.

Sin embargo, al escenario planteado por Habermas se le atribuyen principalmente dos líneas de crítica. En la primera, se pone en tela de juicio la argumentación acerca del criterio con el que el autor defiende la eugenesia negativa y, sin embargo, reprocha la positiva. La segunda línea crítica proviene de aquellos que atribuyen al ambiente un peso tanto o más importante que a la genética en la determinación de la propia conciencia; por lo que la eugenesia liberal no supondría un riesgo nuevo respecto al argumento del cambio de autocomprensión de la especie esgrimido por Habermas.

Entre la primera línea de críticas, autores como Mendieta (2002) y Mosterín (2006) discuten que si la base de nuestra autoconciencia como individuos morales, responsables e iguales, radica en la indisponibilidad de la determinación genética del individuo, por más que Habermas intente marcar la diferencia en base a un hipotético futuro consenso entre los manipuladores (padres) y los manipulados (hijos), no existe una línea o criterio claro que separe la eugenesia negativa de la positiva. Esta crítica la fundamentan en el hecho de que, si bien los futuros sujetos estarían de acuerdo con que se les privara de enfermedades hereditarias, con la misma razón podría suponerse que también desearan que se les hubiera permitido una esperanza de vida más larga, coeficientes intelectuales más elevados, cuerpos más musculosos, etc. Por lo que, si la manipulación 
genética produce perturbaciones en la autocomprensión ética de la especie, lo haría tanto en el seno de una manipulación destinada a una eugenesia positiva como a una negativa. Por tanto, como indica Mendieta (2002), el criterio discursivo, que requiere tener en cuenta un diálogo hipotético con las generaciones futuras, parece desplazar únicamente el locus temporal de nuestro dilema desde el presente al futuro, y ni aun así el problema se resuelve, porque puede que ni siquiera las generaciones futuras supieran si una intervención genética específica fue realizada terapéuticamente o simplemente para mejorar. Y es que, además, la historia nos demuestra que la diferencia entre la enfermedad y la salud, lo patológico y lo normal, están en función de convenciones históricas y culturales.

La otra crítica importante vertida sobre el planteamiento habermasiano es imputable a aquellos que restan trascendencia a la manipulación genética como elemento perturbador para la autocomprensión de la especie, aduciendo que ante esta argumentación cabría otorgar entonces mayor peso al ambiente (De la puente, 2009). Esta línea de crítica entiende que la línea de flotación sobre la que se apoya la argumentación de Habermas, a saber, que el cuadro genético es en gran medida determinista, es errónea. La ciencia apunta a que es la interacción entre gen, organismo y ambiente (conocida como triple hélice) la que da lugar a un ser vivo único (Lewontin, 2000). Al parecer, las variaciones ambientales pueden tener gran impacto sobre la expresión de determinados genes. Esta crítica es apoyada por los partidarios de la eugenesia liberal, quienes defienden que ya hoy en día los padres son libres de mejorar la inteligencia o las capacidades físicas mediante intervenciones sobre factores ambientales basadas en modelos educativos, dietas, complementos vitamínicos y alimenticios de todo tipo, etc. (Agar, 2012).

Esta crítica fue prevista por el filósofo alemán, quien, más o menos acertadamente, proponía distinguir la diferencia entre eugenesia y educación, atribuyendo a la primera un carácter artificial y a la segunda otro natural (Gil Martín, 2005). No obstante, esta relación eugenesia-artificial / educaciónnatural parece ciertamente arbitraria y, en cualquier caso, solo alude a potenciales herramientas de modificación sobre la autoconciencia de uno mismo y de la propia biografía. Por lo que Habermas hace el esfuerzo de aclarar que el hecho diferencial no se centra tanto en la naturaleza o artificialidad del proceso, como en las posibilidades de reversibilidad del mismo:

Llega un día en el que el menor que crece asume la responsabilidad de su biografía y de lo que es él mismo. Puede conducirse reflexivamente respecto a su proceso de formación, desarrollar una autocomprensión revisionaria y hacer la 
tentativa de compensar retrospectivamente la responsabilidad asimétrica que tienen los padres sobre la educación de sus hijos. Esta posibilidad de una apropiación autocrítica de la historia de la propia formación no se da de la misma manera en disposiciones manipuladas genéticamente (p. 26).

El autor entiende, pues, que las metas obtenidas a través del proceso de educación, a diferencia de las eugenésicas, tienen un carácter reversible a partir de un proceso personal de reflexión y revisión; mientras que los cambios producidos por una intervención genética son de carácter irreversible.

En cualquier caso, y para concluir definitivamente estas consideraciones, queremos insistir en que solo el planteamiento de argumentos relativos a la constitución de dos tipos de humanidad: la artificial (genéticamente manipulada) y la natural (genéticamente intacta), instan a la reflexión bioética a irrumpir en escena como actriz protagonista ante los dilemas derivados del avance biotecnológico. Pues, como indica Sarewitz (2011), es plausible que en un futuro no muy lejano las sociedades venideras se enfrenten a este tipo de dilemas, por lo que a la bioética no le queda otra que afrontarlos y tratar de aportar reflexiones que estén a la altura de los tiempos.

\section{Referencias bibliográficas}

Agar, Nicholas. "Eugenesia liberal”, Signos Filosóficos, vol. XIV, núm. 28, 2012, pp. 145-170.

Bobadilla, Francisco. "El futuro de la naturaleza humana. ¿Hacia una eugenesia liberal?", Revista de Comunicación, Vol. I, 2003, pp. 147-149.

Bostrom, Nick. "Una historia del pensamiento transhumanista", Argumentos de razón técnica, núm. 14, 2011, pp. 157-191.

Cortina, Adela. Ética aplicada y democracia radical. Madrid, Tecnos, 1993.

Cortina, Adela. La Escuela de Fráncfort. Crítica y utopía, Síntesis, Madrid, 2008.

De la Puente Sánchez, Javier. "Habermas y la bioética", Foro de Educación, núm. 11, 2009, pp. 167-174.

Diéguez, Antonio. "El determinismo tecnológico: indicaciones para su interpretación”, Argumentos de razón técnica, núm. 8, 2011, pp. 67-87.

García Moreno, Francisco. "La relación ciencia y tecnología en la sociedad actual. Análisis de algunos criterios y valores epistemológicos y tecnológicos y su influencia dentro del marco social”, Argumentos de razón técnica, núm. 7, 2004, pp. 105-148. 
Germán Zurriaraín, R. "El concepto de vida «prepersonal» en el futuro de la naturaleza humana de J. Habermas". Cuadernos de Bioética, Universidad de Navarra. Vol I, 2005.

Gil Antón, Manuel. Colaboración en Seminario sobre la Naturaleza Humana. UNAM y SMTC-CINVESTAV, 2005, http://smtc.cinvestav.mx/200040429.pdf Gil Martin, F.J. "Más allá del desafío transhumanista; Habermas y el peligro de la eugenesia liberal", Revista Observaciones Filosóficas. Northwestern University $2005-2007$

Habermas, Jürgen. Aclaraciones a la ética del discurso. Madrid, Trotta, 2000. Habermas, Jürgen. Ciencia y técnica como ideología, Madrid, Tecnos, 2002. Habermas, Jürgen. El futuro de la naturaleza humana. ¿Hacia una eugenesia liberal?, Barcelona, Paidós, 2002.

Kant, Immanuel. Metafísica de las costumbres, Madrid, Tecnos, 1989.

Lewontin, Richard. C. The Triple Helix: Gene, Organism, and Environment, Cambridge, Mass, Havard University Press, 2000.

López Araiza Bravo, Hugo. "Cómo y por qué una filosofía de la tecnología", Argumentos de razón técnica, núm. 15, 2012, pp. 111-124.

López Baroni, Manuel Jesús. "Los principios no originarios de la bioética", Argumentos de razón técnica, núm. 14, 2011, pp. 113-149.

López Baroni, Manuel Jesús. "Las bioéticas laicas", Argumentos de razón técnica, núm. 16, 2013, pp. 121-161.

Mendieta, Eduardo. "El debate sobre el futuro de la especie humana: Habermas critica la eugenesia liberal", Isegoría, núm. 27, 2002, pp. 91-114.

Moreno Lax, Alejandro. "Jürgen Habermas: entre la ética del discurso y la ética de la especie", Tópicos, núm. 35, 2008, 93-112.

Mosterín, Jesús. La naturaleza humana, Madrid, Espasa Calpe, 2006.

Queraltó, Ramón. "Ética y sociedad tecnológica: pirámide y retícula", Argumentos de razón técnica, núm. 5, 2002, pp. 39-83.

Rius, Mercè. "El futuro de la naturaleza humana. Del fracaso de la intención a la lógica de las consecuencias", Claves de Razón Práctica, 2004, núm. 145, pp.7183.

Sarewitz, Daniel. "Can Technology Make You Better", Argumentos de razón técnica, núm. 14, 2011, pp. 193-209.

Villalaín Blanco, J. D. "El origen de la Bioética y su desarrollo", en G. M. Tomás Garrido, Manual de Bioética, Barcelona, Ariel, 2001, pp. 39-56.

Villalobos Antúnez, José Vicente; Bello, Mariadela. "Ética para una sociedad global: la bioética puente para el giro tecnocientífico", Revista Lasallista de Investigación, Vol. 11, núm. 1, 2014, pp. 70-77. 